See discussions, stats, and author profiles for this publication at: https://www.researchgate.net/publication/273863260

\title{
Starch-based gel electrolyte thin films derived from native sago (Metroxylon sagu) starch
}

Article in lonics · October 2014

Dol: 10.1007/s11581-014-1092-5

\section{CITATIONS}

6

3 authors:

Suh Cem Pang

University Malaysia Sarawak

67 PUBLICATIONS 2,136 CITATIONS

SEE PROFILE

$=$

Suk Fun Chin

University Malaysia Sarawak

77 PUBLICATIONS 1,362 CITATIONS

SEE PROFILE

Some of the authors of this publication are also working on these related projects:

Design of antimicrobials View project

Chemical modification of sago hampas as absorbents for $\mathrm{ZnO}$ nanoparticles View project
484

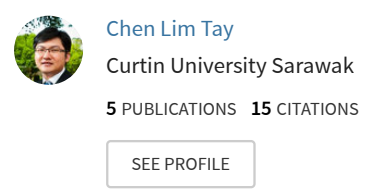




\title{
Starch-based gel electrolyte thin films derived from native sago (Metroxylon sagu) starch
}

\author{
Suh Cem Pang • Chen Lim Tay $\cdot$ Suk Fun Chin
}

Received: 9 October 2013 /Revised: 14 February 2014 / Accepted: 17 February 2014

(C) Springer-Verlag Berlin Heidelberg 2014

\begin{abstract}
Starch-based gel electrolyte (SbGE) thin films were prepared by mixing native sago starch with different amounts of glycerol, and subsequently doped with various types of ionic salts. SbGE thin films showed substantially enhanced mechanical properties and ionic conductivity through incorporating optimal composition of native sago starch, glycerol, and ionic salts. A maximum room temperature ionic conductivity of the order of $10^{-3} \mathrm{~S} \mathrm{~cm}^{-1}$ was achieved for optimized SbGE thin film consisting of $80 \mathrm{wt} \%$ of native sago starch and $20 \mathrm{wt} \%$ of glycerol, and doped with $8 \mathrm{wt} \%$ of $\mathrm{LiCl}$. SbGE thin films were characterized by Fourier transformed infrared spectrometry, scanning electron microscopy, and electrochemical impedance spectroscopy. Due to their favorable mechanical properties, high ionic conductivity at room temperature, ease of preparation, environmentally benign, and cheap, SbGE thin films show high potential utility as gel electrolyte materials for the fabrication of solid-state electrochemical devices.
\end{abstract}

Keywords Native sago starch $\cdot$ Gel electrolyte $\cdot$ Ionic conductivity $\cdot$ Plasticizer $\cdot$ Ionic salts

\section{Introduction}

Solid polymer electrolyte (SPE) is a type of electrolyte material that has been developed to replace conventional liquid electrolyte in various electrochemical devices such as

S. C. Pang $(\bowtie) \cdot$ S. F. Chin

Department of Chemistry, Faculty of Resource Science and

Technology, Universiti Malaysia Sarawak, 94300 Kota Samarahan,

Sarawak, Malaysia

e-mail: suhcem@gmail.com

C. L. Tay

School of Engineering and Science, Curtin University Sarawak, Miri, Malaysia rechargeable batteries, supercapacitor, and electrochromic window $[1,2]$. SPE behaves as an ionic conductor that allows ions to move between two electrodes during electrochemical reactions and serves as a separator for both electrodes at the same time. Among the advantages of SPE as compared to conventional liquid electrolytes include prevention of internal short-circuiting due to formation of dendrites, leakage of electrolyte, and volume expansion due to electrochemical reactions on the electrolyte/electrode interface, and reactive explosion [3]. The development of SPE has led to improved overall safety, portability, and durability of various electrochemical devices.

Various synthetic polymers such as poly(ethylene oxide) (PEO), poly(acrylonitrile) (PAN), poly(methyl methacrylate) (PMMA), poly(vinylidene fluoride) (PVdF), and poly(vinylidene fluoride-hexafluoro propylene) (PVdF-HFP) have been used as the polymeric matrices for polymer electrolyte [4-7]. Besides synthetic polymers, natural biopolymers such as starch and cellulose which are abundant, renewable, and cheap constitute attractive alternatives for the development of SPE [8-10]. However, the current utilization of biopolymers in the development of SPE was not widely studied. Lopes et al. [11] reported the preparation of gel electrolyte from high amylose starch with an ionic conductivity of $5 \times$ $10^{-5} \mathrm{~S} \mathrm{~cm}^{-1}$ at room temperature. Such level of ionic conductivity has failed to meet the requirement of various electrochemical device applications which required an ionic conductivity of $10^{-3} \mathrm{~S} \mathrm{~cm}^{-1}$ and above.

In this study, starch-based gel electrolyte (SbGE) in the form of flexible, conformal, and ionically conductive thin films was prepared from native sago starch powder. Native sago (Metroxylon sagu) starch shows similar physicochemical properties as those of cassava and sweet potato starches such as granular size, moisture content, swelling power, solubility, and gelatinization temperature $[12,13]$. Being environmentally benign and cheap, optimized SbGE thin films of enhanced 